\title{
Electronic structure, chemical bonding features, and electron charge density of the double-cubane single crystal $\left[\mathrm{Sb}_{7} \mathrm{~S}_{8} \mathrm{Br}_{2}\right]\left(\mathrm{AlCl}_{4}\right)_{3}$
}

\author{
Ali H. Reshak, ${ }^{1,2, a)}$ H. Kamarudin, ${ }^{2, b)}$ S. Auluck, ${ }^{3, c)}$ B. Minofar, ${ }^{4, d)}$ and I. V. Kityk ${ }^{5, e)}$ \\ ${ }^{1}$ Institute of Physical Biology, South Bohemia University, Nove Hrady 37333, Czech Republic \\ ${ }^{2}$ School of Material Engineering, Malaysia University of Perlis, P.O. Box 77, d/a Pejabat Pos Besar, \\ 01007 Kangar, Perlis, Malaysia \\ ${ }^{3}$ National Physical Laboratory, Dr. K S Krishnan Marg, New Delhi 110012, India \\ ${ }^{4}$ Department of Chemistry, Faculty of Science, Kyushu University, Hakozaki, Higashi-ku, 6-10-1, \\ Fukuoka city 812-8581, Japan \\ ${ }^{5}$ Department of Electrical Engineering, Technological University of Czestochowa, Al.Armii Krajowej 17/19, \\ Czestochowa, Poland
}

(Received 3 March 2011; accepted 8 April 2011; published online 16 May 2011)

\begin{abstract}
The present calculations were performed using all-electron full potential linearized augmented plane wave method based on the density functional theory. We have optimized the structure of the double-cubane single crystal $\left[\mathrm{Sb}_{7} \mathrm{~S}_{8} \mathrm{Br}_{2}\right]\left(\mathrm{AlCl}_{4}\right)_{3}$, starting with the x-ray diffraction data Zhang et al., [J. Am. Chem. Soc. 131, 9896 (2009)], by minimization of the forces (1 mRy/au) acting on the atoms, keeping the lattice parameters fixed at the experimental values. Our calculations show that $\left[\mathrm{Sb}_{7} \mathrm{~S}_{8} \mathrm{Br}_{2}\right]\left(\mathrm{AlCl}_{4}\right)_{3}$ possesses a wide indirect energy band gap of about $1.6 \mathrm{eV}(2.03 \mathrm{eV})$ using local density approximation (Engel-Vosko generalized gradient approximation) exchange correlation potentials. To describe the bonding properties we have evaluated the electronic charge space density contour in four planes-namely (001), (110), (100), and (010) which show that this compound possesses a considerable anisotropy. The contour plot shows partial ionic and strong covalent bonding between $\mathrm{S}-\mathrm{Sb}, \mathrm{Al}-\mathrm{Cl}, \mathrm{S}-\mathrm{Br}, \mathrm{S}-\mathrm{S}, \mathrm{Cl}-\mathrm{Cl}$, and $\mathrm{Sb}-\mathrm{Br}$ atoms. (C) 2011 American Institute of Physics. [doi:10.1063/1.3583674]
\end{abstract}

Ionic liquids as supersolvents are now recognized as powerful reaction media for preparing functional materials such as zeolites, ${ }^{1}$ metal-organic frameworks, ${ }^{1}$ metal nanoparticles, ${ }^{2}$ and organic compounds ${ }^{3}$ as well as being useful in separations, ${ }^{4}$ electrochemistry, ${ }^{5}$ and nanotechnology. ${ }^{6}$ Chalcogenides have not only diverse structures but also technologically promising properties such as thermoelectric and solar energy conversion, ${ }^{7}$ phase change transitions liquids could offer fascinating possibilities for producing new structure in chalcogenides and unprecedented properties. ${ }^{8}$ Recently Zhang et al. ${ }^{8}$ demonstrated the use of the ionic liquid $\mathrm{EMIMBr}-\mathrm{AlCl}_{3}(\mathrm{EMIM}=1$-ethyl-3-methylimid-azolium $)$ as solvent in the preparation of a material featuring a cationic chalcogenide. They reported the synthesis of cationic chalcogenide clusters in ionic liquids and showed that chalcogenide polycationic clusters can be conveniently synthesized in ionic liquid media containing Lewis acids or strong acceptors. They found that the red crystals of $\left[\mathrm{Sb}_{7} \mathrm{~S}_{8} \mathrm{Br}_{2}\right]\left(\mathrm{AlCl}_{4}\right)_{3}$ exhibit nonlinear optical properties, including differencefrequency generation and second harmonic generation (SHG).

The single crystal of $\left[\mathrm{Sb}_{7} \mathrm{~S}_{8} \mathrm{Br}_{2}\right]\left(\mathrm{AlCl}_{4}\right)_{3}$ crystallizes in the noncentrosymmetric orthorhombic space group $P 2_{1} 2_{1} 2_{1}$, with $\quad Z=4, \quad a=11.989(2) \AA, \quad b=16.896(3) \AA, \quad c$ $=17.378(4) \AA$, and $v=3520.2(12) \AA^{3}$. The crystal structure of $\left[\mathrm{Sb}_{7} \mathrm{~S}_{8} \mathrm{Br}_{2}\right]\left(\mathrm{AlCl}_{4}\right)_{3}$ is shown in Fig. 1(a). It consists of

\footnotetext{
a) Author to whom correspondence should be addressed. Tel.: +420 777729583. FAX: +420-386 361231. Electronic mail: maalidph@yahoo.co.uk.

b) Electronic mail: vc@unimap.edu.my.

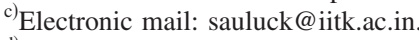

${ }^{\mathrm{d})}$ Electronic mail: minofar@chem.kyushu-univ.jp.

${ }^{\text {e)} E l e c t r o n i c ~ m a i l: ~ i w a n k 74 @ g m a i l . c o m . ~}$
}

cationic $\left[\mathrm{Sb}_{7} \mathrm{~S}_{8} \mathrm{Br}_{2}\right]^{3+}$ clusters and $\left[\mathrm{AlCl}_{4}\right]^{-}$anions. Each cluster adopts a unique double-cubane structure in which two distorted cubic clusters connect by sharing one corner-Sb1 site. The other corners are alternately occupied with $\mathrm{Sb}$ and $\mathrm{S}$ atoms. Two $\mathrm{Sb}$ sites ( $\mathrm{Sb} 2$ and $\mathrm{Sb} 6$ ) have terminal $\mathrm{Sb}-\mathrm{Br}$ bonds projecting out of the cluster structure (see Fig. 1(a)). For more details we refer the reader to Ref. 8.

The present calculations were performed using allelectron full potential linearized augmented plane wave method based on the density functional theory ${ }^{9}$ as implemented in WIEN2K code. ${ }^{10}$ We have optimized the crystal structure of $\left[\mathrm{Sb}_{7} \mathrm{~S}_{8} \mathrm{Br}_{2}\right]\left(\mathrm{AlCl}_{4}\right)_{3}$, starting from the atomic positions taken from the XRD data, ${ }^{8}$ by minimization of the forces $[1 \mathrm{mRy} /$ atomic units (a.u.) $]$ acting on the atoms. From the relaxed geometry the electronic structure and the chemical bonding can be determined and various spectroscopic features can be simulated and compared with experimental data. Once the forces are minimized in this construction one can then find the self-consistent density at these positions by turning off the relaxations and driving the system to selfconsistency. For the exchange and correlation potential the local density approximation (LDA) by Ceperley-Alder, ${ }^{11}$ which is based on exchange-correlation energy optimization to calculate the total energy, was employed. In addition, we have used the Engel-Vosko generalized gradient approximation (EV-GGA), ${ }^{12}$ which optimizes the corresponding potential for electronic band-structure calculations. Self-consistency was achieved by use of 400 $\mathrm{k}$-points in the Brillouin zone (BZ). The densities of states is calculated using $500 \mathrm{k}$-points in the BZ. The self-consistent calculations are converged since the total energy of the system is stable within $10^{-5} \mathrm{Ry}$.

We first discus our results pertaining to the electronic properties of $\left[\mathrm{Sb}_{7} \mathrm{~S}_{8} \mathrm{Br}_{2}\right]\left(\mathrm{AlCl}_{4}\right)_{3}$ via the total and the angular 


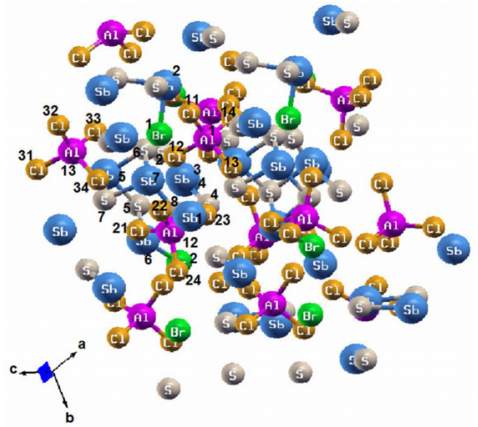

(a)

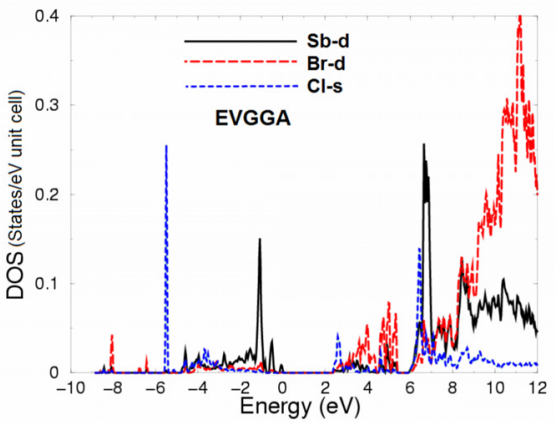

(d)

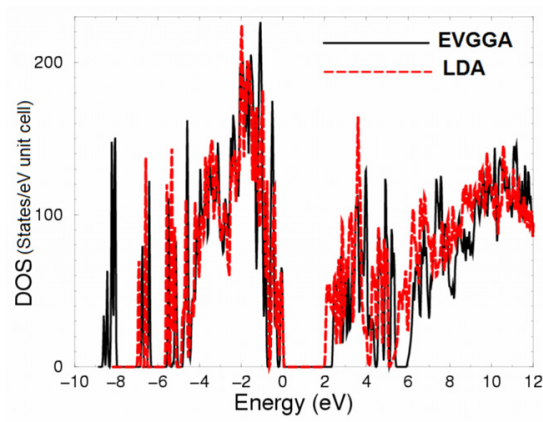

(b)

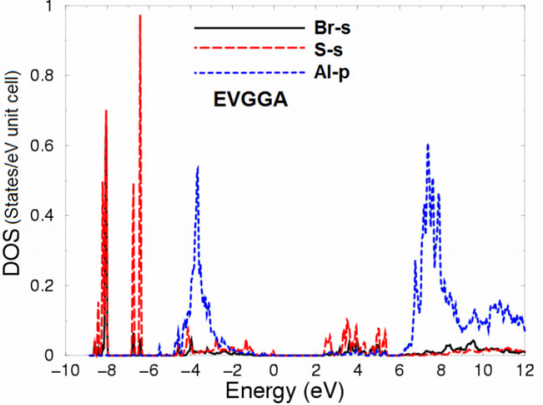

(e)

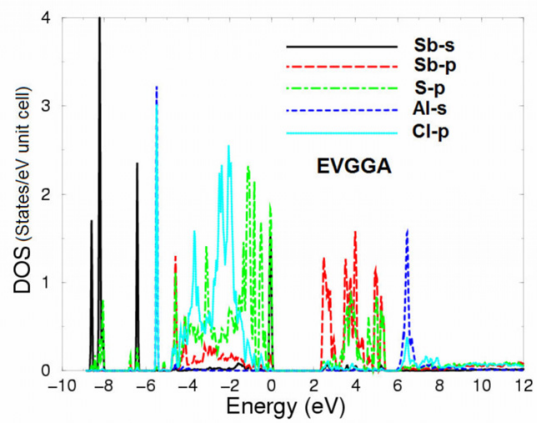

(c)

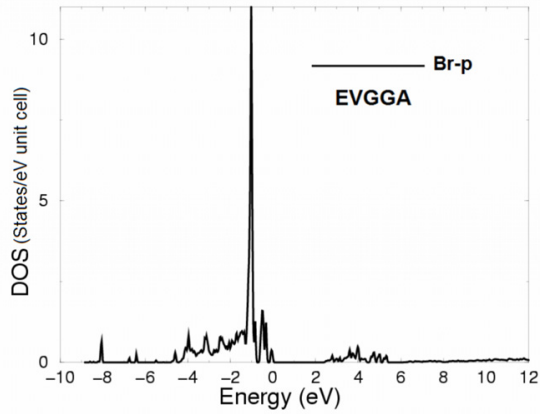

(f)

FIG. 1. (Color online) (a) Crystal structure of $\left[\mathrm{Sb}_{7} \mathrm{~S}_{8} \mathrm{Br}_{2}\right]\left(\mathrm{AlCl}_{4}\right)_{3}$. (b-f) Calculated total and partial densities of states (states per electron volt unit cell).

momentum resolved projected density of states (PDOS). Following the total and partial density distributions of state PDOS [Figs. 1(b)-1(f)] one can identify the different features of the band states. These figures suggest that $\left[\mathrm{Sb}_{7} \mathrm{~S}_{8} \mathrm{Br}_{2}\right]\left(\mathrm{AlCl}_{4}\right)_{3}$ possesses a wide indirect energy band gap equal to about $1.6 \mathrm{eV}(2.03 \mathrm{eV})$ using LDA (EV-GGA) approaches. The well-known LDA underestimation of the band gaps is attributed to the fact that the LDA Kohn-Sham states do not take into account the quasiparticle self-energy correctly. To avoid this problem we have used the EV-GGA approach which is able to reproduce better exchange potential at the expense of less agreement in the exchange energy. This approach yields better band splitting compared to LDA.

Figure 2(a) presents the calculated total electronic density of states using LDA in comparison with EV-GGA. The most prominent features of the calculated electronic density of states for $\left[\mathrm{Sb}_{7} \mathrm{~S}_{8} \mathrm{Br}_{2}\right]\left(\mathrm{AlCl}_{4}\right)_{3}$ are the band gap and bandwidths. We should emphasize that there is a small difference between the two mentioned approximations with respect to the bandwidth, magnitudes and the spectral peaks positions. It is necessary to emphasize that the EV-GGA approach causes spectral shifts in the conduction band minimum (CBM) toward higher energies with respect to Fermi energy $\left(\mathrm{E}_{\mathrm{F}}\right)$ by around $0.5 \mathrm{eV}$ keeping the top of the valence band fixed at the same energy position. A remarkable fact of $\left[\mathrm{Sb}_{7} \mathrm{~S}_{8} \mathrm{Br}_{2}\right]\left(\mathrm{AlCl}_{4}\right)_{3}$ is that the cationic $\left[\mathrm{Sb}_{7} \mathrm{~S}_{8} \mathrm{Br}_{2}\right]^{3+}$ clusters are packed in pseudohexagonally arranged columns along the crystallographic a-axis and display a pronounced hexagonal pseudosymmetry. The double-cubane single crystal possesses the empirical formula $\left[\mathrm{Sb}_{7} \mathrm{~S}_{8} \mathrm{Br}_{2}\right]\left(\mathrm{AlCl}_{4}\right)_{3}$ with 32 atoms per unit cell. In order to understand the contribution of each orbital of each atom in $\left[\mathrm{Sb}_{7} \mathrm{~S}_{8} \mathrm{Br}_{2}\right]\left(\mathrm{AlCl}_{4}\right)_{3}$ we thought it would worthwhile to investigate the angular momentum decomposition of the atoms PDOS. Following the PDOS we are able to identify the angular momentum characters of various structures. We should emphasize that the valence band maximum (VBM) is composed of $\mathrm{Sb} s$ and $\mathrm{S} p$ states, while the $\mathrm{CBM}$ originates from $\mathrm{Sb} s, \mathrm{Cl} p, \mathrm{Sb} s$, and $\mathrm{S} p$ states. The $\mathrm{S} p$ and $\mathrm{Sb} s$ characters are concentrated in the upper valence band, with only small amounts in the conduction band. The existence of $\mathrm{S} p$ and $\mathrm{Sb} s$ character in the upper valence band has a significant consequence for the optical band gap, while the bottom of the conduction band is formed prevailingly from $\mathrm{Sb} p$ states and small contribution of $\mathrm{Cl} p, \mathrm{~S} p$, and $\mathrm{Sb} s$. The structures at lower energies between -9.0 up to $-8.0 \mathrm{eV}$ are mainly $\mathrm{Sb} s$ states with small admixture of $\mathrm{S} p$ and $\mathrm{S} s$ states. In the energy region between -7.0 up to $-5.0 \mathrm{eV}$ one can see that the $\mathrm{Sb} s, \mathrm{Al} s$, $\mathrm{Cl} p$ states are the main contributors with very small admixture of $\mathrm{S} s / p$ and $\mathrm{Cl} s$ states. The bands from $-5 \mathrm{eV}$ up to

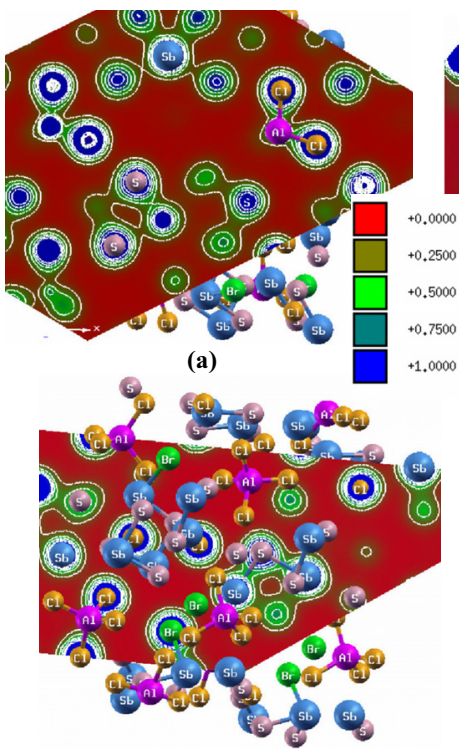

(c)

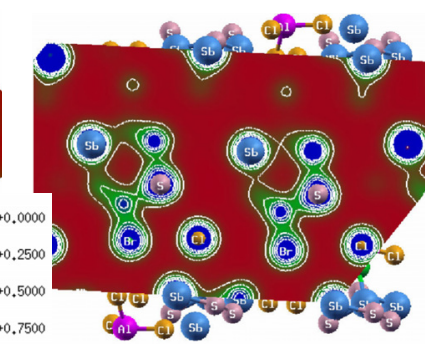

(b)

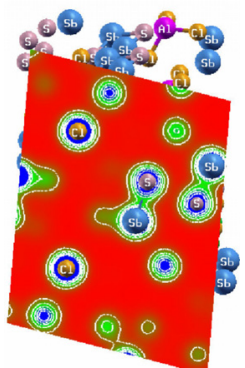

(d)
FIG. 2. (Color online) The electronic charge density contour: (a) in the (101) plane; (b) in the (001) plane; (c) in the (110) plane; (d) in the (100) plane. 
$\mathrm{E}_{\mathrm{F}}$ are predominately $\mathrm{Br} p, \mathrm{~S} p$, and $\mathrm{Sb} s / p$ states with small contributions from $\mathrm{Sb} d$ and $\mathrm{Al} p$ states. At higher energies, from the CBM and above, there is admixture of $\mathrm{Sb} p, \mathrm{~S} p, \mathrm{Al} s, \mathrm{Cl} p$ with negligible amount of $\mathrm{Sb} s$, $\mathrm{Br} d, \mathrm{Sb} d, \mathrm{Cl} s$, and $\mathrm{Al} p$ states. The angular momentum decomposition of the atoms PDOS show that there are strong hybridizations between different states. Around $-8.0 \mathrm{eV}$ the $\mathrm{Sb} s$ states hybridized with $\mathrm{S} p$ states, $\mathrm{S} s$ with $\mathrm{Br} s$ states. $\mathrm{Cl} p$ and $\mathrm{Al} s$ show strong hybridization around $-5.0 \mathrm{eV}$, $\mathrm{Sb} p$ and $\mathrm{S} p$ states hybridize with $\mathrm{Cl} p$ states and $\mathrm{Cl} s$ hybridize with $\mathrm{Sb} d$ at $-4.5 \mathrm{eV}$. Around $-1.0 \mathrm{eV}, \mathrm{Cl} p$ states hybridize with $\mathrm{S} p$ states and at $+3.0 \mathrm{eV}, \mathrm{Br} d$ hybridize with $\mathrm{Sb} d$ states. At $+4.0 \mathrm{eV}, \mathrm{Sb} p$ states hybridized with $\mathrm{S} p$ states, and at $+6.5 \mathrm{eV}, \mathrm{Cl} s$ with $\mathrm{Sb} d$. Finally in the energy range from +7.0 up to $+9.0 \mathrm{eV}, \mathrm{Br} d$ hybridizes with $\mathrm{Sb} d$ states.

With the aid of the calculated electron charge density, we obtained an image of the electron clouds that surround the molecules in the unit cell. We hope that this image will allow us to discuss the chemical bonding features. The origin of chemical bonding can be elucidated following the total and the angular momentum decomposition of the atoms PDOS (Fig. 1(c)-1(f)). Integrating the latter from $-6.0 \mathrm{eV}$ up to $E_{F}$ we obtain the total number of electrons per electron volt for each atom; $\mathrm{Br}$ atoms states (12.0 electrons/eV), $\mathrm{Al}$ atom states (3.5 electrons/eV), $\mathrm{Cl}$ atoms states (3.0 electrons/eV), $\mathrm{S}$ atoms states (2.5 electrons/eV), and $\mathrm{Sb}$ atoms states (1.4 electrons/eV). These results show that some electrons from $\mathrm{Br}, \mathrm{Al}, \mathrm{Cl}, \mathrm{S}$, and $\mathrm{Sb}$ atoms are transferred into valence bands and contribute in covalence interactions between $\mathrm{Br}-\mathrm{Br}, \mathrm{Al}-$ $\mathrm{Al}, \mathrm{Cl}-\mathrm{Cl}, \mathrm{S}-\mathrm{S}$, and $\mathrm{Sb}-\mathrm{Sb}$ atoms, and substantial covalent interactions between $\mathrm{S}-\mathrm{Sb}, \mathrm{Al}-\mathrm{Cl}, \mathrm{S}-\mathrm{Br}, \mathrm{S}-\mathrm{S}, \mathrm{Cl}-\mathrm{Cl}$, and $\mathrm{Sb}-\mathrm{Br}$ atoms. The covalent bond arises due to the degree of the hybridization. It is clear that there is an interaction of charges between $\mathrm{S}-\mathrm{Sb}, \mathrm{Al}-\mathrm{Cl}, \mathrm{S}-\mathrm{Br}, \mathrm{S}-\mathrm{S}, \mathrm{Cl}-\mathrm{Cl}$, and $\mathrm{Sb}-\mathrm{Br}$ atoms due to the strong hybridization, thus showing that there is a strong covalent bonding between these atoms. Thus the electronic densities of states help us to analyze the nature of the bonds according to the classical chemical concept. This concept is very useful to classify compounds into different categories with respect to different chemical and physical properties. To support this statement we have taken a more careful look at the bonding situation since the existence of real hybridization between states of atoms should lead to covalent bond's origin between these atoms. The calculated $\mathrm{Al}-\mathrm{Cl}$ bond lengths for the optimized structure are range from 2.1 to $2.19 \AA$ in good agreement with the measured ones $[2.093(4)$ to $2.167(3) \AA] .{ }^{8}$ The calculated $\mathrm{Cl}-$ $\mathrm{Al}-\mathrm{Cl}$ angles are range from $107.0^{\circ}$ to $113.2^{\circ}$ in good agreement with the measured ones $\left[106.22(14)^{\circ} \text { to } 112.73(15)^{\circ}\right]^{8}$ The calculated bond lengths are listed in Table I along with the experiment. ${ }^{8}$

To describe the bonding properties of $\left[\mathrm{Sb}_{7} \mathrm{~S}_{8} \mathrm{Br}_{2}\right]$ $\times\left(\mathrm{AlCl}_{4}\right)_{3}$ we have studied the electronic charge density contour in four planes-namely (001), (110), (100), and (010) planes as shown in Fig. 2. Following these contour plots one can see that the planes (001) and (110) presents four kinds atoms out of the five kinds namely $(\mathrm{Al}, \mathrm{Cl}, \mathrm{Sb}$, and $\mathrm{S})$ and $(\mathrm{Br}, \mathrm{Cl}, \mathrm{Sb}, \mathrm{S})$, respectively. The other two planes (100) and (010) presents only three kinds of atoms namely $(\mathrm{Cl}, \mathrm{Sb}$, and $\mathrm{S})$, suggest that $\left[\mathrm{Sb}_{7} \mathrm{~S}_{8} \mathrm{Br}_{2}\right]\left(\mathrm{AlCl}_{4}\right)_{3}$ possesses a considerable
TABLE I. Selected bond lengths (optimized structure) in comparison with experimental data (Ref. 8).

\begin{tabular}{lcc}
\hline \hline $\begin{array}{c}\text { Bond length } \\
(\AA)\end{array}$ & Exp. & $\begin{array}{c}\text { This work } \\
\text { (optimized structure) }\end{array}$ \\
\hline Sb1-S3 & $2.599(2)$ & 2.62 \\
Sb1-S8 & $2.628(2)$ & 2.69 \\
Sb1-S4 & $2.695(2)$ & 2.71 \\
Sb1-S7 & $2.747(2)$ & 2.98 \\
Sb1-S1 & $2.948(3)$ & 2.99 \\
Sb1-S5 & $2.996(3)$ & 3.00 \\
Sb2-S2 & $3.135(3)$ & 3.15 \\
Sb6-S6 & $3.136(4)$ & 3.15 \\
\hline \hline
\end{tabular}

anisotropy. Generally a crystal which shows considerable anisotropy favors an enhanced phase matching conditions necessary for the SHG and optical parametric oscillator (OPO). ${ }^{13}$

The contour plot shows partial ionic and strong covalent bonding between $\mathrm{S}-\mathrm{Sb}, \mathrm{Al}-\mathrm{Cl}, \mathrm{S}-\mathrm{Br}, \mathrm{S}-\mathrm{S}, \mathrm{Cl}-\mathrm{Cl}$, and $\mathrm{Sb}-\mathrm{Br}$ atoms depending on Pauling electronegativity difference of $\mathrm{S}$ (2.58), $\mathrm{Sb}$ (2.05), $\mathrm{Al}$ (1.61), $\mathrm{Br}$ (2.96), and $\mathrm{Cl}$ (3.16) atoms (see Fig. 2). From these contour plots one can see that the majority of $\mathrm{S}, \mathrm{Sb}, \mathrm{Al}$, and $\mathrm{Br}$ electronic charge is transferred to $\mathrm{Cl}$ atom. The charge density along $\mathrm{S}-\mathrm{Sb}, \mathrm{Al}-\mathrm{Cl}, \mathrm{S}-\mathrm{Br}$, $\mathrm{S}-\mathrm{S}, \mathrm{Cl}-\mathrm{Cl}$, and $\mathrm{Sb}-\mathrm{Br}$ atoms is pronounced. This is due to the strong hybridization of covalent $\mathrm{S}-\mathrm{Sb}, \mathrm{Al}-\mathrm{Cl}, \mathrm{S}-\mathrm{Br}, \mathrm{S}-\mathrm{S}$, $\mathrm{Cl}-\mathrm{Cl}$, and $\mathrm{Sb}-\mathrm{Br}$ bonds. We should emphasize that the charge density distribution is essentially spherical around all the atoms. The $\mathrm{Cl}$ atom is more electronegative than $\mathrm{Al}, \mathrm{Sb}$, $\mathrm{S}$, and $\mathrm{Br}$ atoms, as one can clearly see that the charge accumulates more near $\mathrm{Cl}$ along the bonds and the charge around $\mathrm{Cl}$ uniformly distributed.

This work was supported from the institutional research concept of the Institute of Physical Biology, UFB (Grant No. MSM6007665808), the program RDI of the Czech Republic, the project CENAKVA (Grant No. CZ.1.05/2.1.00/01.0024), the Grant No. 152/2010/Z of the Grant Agency of the University of South Bohemia. School of Material Engineering, Malaysia University of Perlis.

${ }^{1}$ R. E. Morris, Angew. Chem., Int. Ed. 47, 442 (2008).

${ }^{2}$ P. Migowski and J. Dupont, Chem.-Eur. J. 13, 32 (2007); A. M. Guloy, R. Ramlau, Z. Tang, W. Schnelle, M. Baitinger, and Y. Grin, Nature (London) 443, 320 (2006).

${ }^{3}$ M. Haumann and A. Riisager, Chem. Rev. 108, 1474 (2008); P. Tundo and A. Perosa, Chem. Soc. Rev. 36, 532 (2007).

${ }^{4}$ X. Han and D. W. Armstrong, Acc. Chem. Res. 40, 1079 (2007).

${ }^{5}$ S. Z. El Abedin and F. Endres, Acc. Chem. Res. 40, 1106 (2007).

${ }^{6}$ T. P. Lodge, Science 321, 50 (2008).

${ }^{7}$ K. F. Hsu, S. Loo, F. Guo, W. Chen, J. S. Dyck, C. Uher, T. Hogan, E. K. Polychroniadis, and M. G. Kanatzidis, Science 303, 818 (2004).

${ }^{8}$ Q. Zhang, I. Chung, J. I. Jang, J. B. Ketterson, and M. G. Kanatzidis, J. Am. Chem. Soc. 131, 9896 (2009).

${ }^{9}$ P. Hohenberg and W. Kohn, Phys. Rev. B 136, B864 (1964).

${ }^{10}$ P. Blaha, K. Schwarz, G. K. H. Madsen, D. Kvasnicka, and J. Luitz, WIEN2K: An Augmented Plane Wave + Local Orbitals Program for Calculating Crystal Properties (Karlheinz Schwarz, Techn. Universitat, Wien, Austria, 2001)

${ }^{11}$ D. M. Ceperley and B. I. Ader, Phys. Rev. Lett. 45, 566 (1980); Parametrized in J. P. Perdew and A. Zunger. Phys. Rev. B 8, 4822 (1973).

${ }^{12}$ E. Engel and S. H. Vosko, Phys. Rev. B 47, 13164 (1993).

${ }^{13}$ W. T. A. Harrison, M. L. F. Phillips, and G. D. Stucky, Chem. Mater. 7, 1849 (1995) 